\title{
Long-term use of solifenacin in pediatric patients with overactive bladder: Extension of a prospective open-label study
}

\author{
Geneviève Nadeau, MD; ${ }^{*}$ Annette Schröder, MD, ${ }^{\dagger}$ Katherine Moore, MD; ${ }^{*}$ Lucie Genois, MD; ${ }^{*}$ \\ Pascale Lamontagne, MD; Micheline Hamel, MD; Ėve Pellerin, MD; ${ }^{*}$ Stéphane Bolduc, MD, FRCSC
}

"Division of Urology, Centre Hospitalier Universitaire de Québec (CHUQ), Université Laval, Québec, QC; 'Department of Urology, Hospital for Sick Children, Toronto, ON

See related article on page 124.

Cite as: Can Urol Assoc J 2014;8(3-4):118-23. hitp://dx.doi.org/10.5489/cuaj.1356

Published online April 14, 2014.

\section{Abstract}

Introduction: We evaluate the efficacy and safety of solifenacin to treat incontinence in children with non-neurogenic (DO) or neurogenic detrusor overactivity (NDO) refractory to oxybutinin or tolterodine.

Methods: We updated and extended our previously published nonrandomized uncontrolled study on open-label use of adjusted-dose regimens of solifenacin (1.25-10 mg) in children with refractory incontinence. The follow-up included voiding diaries, post-void residuals, urine cultures, ultrasounds and urodynamic studies. Clinical data were updated as of September 2012. Subjective improvement was assessed with the Patient Perception of Bladder Condition (PPBC) scale. The primary end point was efficacy toward continence and secondary end points were tolerability and safety. Results: Overall, 244 patients (112 girls, 132 boys) were enrolled; 53 with NDO and 191 with DO. Minimal follow-up was 5 months, the mean duration of treatment was 21.0 months and the mean age at initiation was 9.2 years. Urodynamic capacity improved from $145 \pm 76 \mathrm{~mL}$ to $339 \pm 152 \mathrm{~mL}$ and the amplitude of uninhibited contractions decreased from $66 \pm 26$ to $20 \pm 20 \mathrm{cmH}_{2} \mathrm{O}(p<0.0001)$. The overall success rate is $91 \%$, and more specifically $94 \%$ for non-neurogenic and $79 \%$ for neurogenic, which is significantly different $(p=0.013)$. Twenty-three patients discontinued treatment for unsatisfactory clinical response or bothersome side effects. No side effects were reported by 175 patients, mild by 46, moderate by 9 , and 14 withdrew due to their side effects. Ten patients developed post-void residuals of $\geq 20 \mathrm{~mL}$.

Conclusion: Although higher in the non-neurogenic group, high subjective and objective success rates were maintained over a longer follow-up with an adjusted-dose regimen of solifenacin to treat pediatric NDO or DO refractory to oxybutynin or tolterodine. Moreover, we found acceptable tolerability and safety profiles.

\section{Introduction}

Overactive bladder $(\mathrm{OAB})$ is frequently encountered in children, with a prevalence of $1 \%$ to $9.2 \% .{ }^{1}$ Most urologists use a stepped approach to address these conditions, starting with the least invasive therapy (behaviour modification and biofeedback) and to more invasive and/or costly interventions (medication, botulinum toxin, neuromodulation, surgery). ${ }^{2}$

Antimuscarinics represent the mainstay of pharmacologic treatment for both idiopathic (DO) and neurogenic (NDO) overactive bladder. ${ }^{3}$ Seven different anticholinergics are currently marketed for the treatment of DO/NDO in adults (oxybutynin, tolterodine, trospium, darifenacin, solifenacin, propiverine and fesoterodine), but none of them has been shown superior to another. ${ }^{4}$

Data about the safety and efficacy of newer agents in children are scarce. Although there have been reports about the use of tolterodine, ${ }^{5-9}$ trospium $^{10}$ and propiverine ${ }^{11,12}$ in children, to date only oxybutynin chloride has been officially approved for pediatric use by medical authorities in North America. Solifenacin is a tertiary amine approved by the FDA for OAB in adults since 2005. It has excellent bioavailability, a long half-life ${ }^{13}$ and potentially a superior side-effect profile due to subtype receptor selectivity for the bladder. ${ }^{14}$

We prospectively studied a cohort of pediatric patients with DO/NDO refractory or intolerant to adjusted oxybutinin or tolterodine treatment and intended to optimize the medical therapy by introducing solifenacin (Vesicare, Astellas). Our previous report was on 72 patients. ${ }^{15}$ We now present the long-term use and extension of our open-label study. More patients were recruited and data from previously enrolled patients were updated as of September 2012. Efficacy, tolerability, safety, and patients/parents satisfaction were assessed. 


\section{Methods}

Patients were prospectively enrolled and followed for a minimum of 5 months after initiation of solifenacin. We included children with neurogenic and non-neurogenic $O A B$ in whom intensive optimized medical (oxybutynin or tolterodine) and behavioural therapies demonstrated only partial clinical and urodynamic (UDS) responses or significant side effects. This study was approved by our institutional ethic board committee and informed consent was obtained.

Before the study as the baseline treatment, all patients were placed on a behavioural protocol. Anticholinergic medication was initiated in patients whose symptoms did not improve after 6 months of strict bladder retraining or whose bladder had less than $65 \%$ of its expected capacity based on age $(30+\text { [age in years } \times 30 \text { ] } \mathrm{mL})^{16}$ and based on a 3 -day voiding diary. The first anticholinergic prescribed was oxybutinin or tolterodine. If the child was able to swallow a capsule, the long-acting formulation was preferred to optimize compliance. The dose of the chosen anticholinergic was increased until resolution of symptoms or appearance of intolerable side effects.

In total, we included 146 patients with either persistent incontinence and 98 patients with significant side effects with oxybutinin or tolterodine. Urodynamic studies were obtained 10 to 14 days after all anticholinergic medications were discontinued and the presence of detrusor contractions during the filling phase (rise of $>15 \mathrm{cmH}_{2} \mathrm{O}$ above baseline) was confirmed in all children. Patients entered a prospective open-label protocol using an adjusted-dose regimen of solifenacin (1.25-10 mg). Subsequent changes in dosage were done as necessary, in consultation with the patient/parents, during regular 3-month follow-ups based on the persistence of symptoms and side effect profile. If needed, solifenacin was either maintained or increased to a maximum of $10 \mathrm{mg}$, given that the patient had not experienced drug-related side effects and demonstrated a compliance rate of $>80 \%$.

Before patients starting treatment, we obtained clinical history, physical exam, 3-day voiding diary, urodynamic studies and abdominal ultrasound. Voiding cystourethrogram (VCUG) was performed for NDO patients and DO patients with a history of urinary tract infection (UTI).

During our systematic 3-month follow-up, patients were re-evaluated with a questionnaire, physical exam, 3-day voiding diary, post-void residual (PVR), urinalysis and cultures. Every 6 months, abdominal ultrasound and UDS were repeated; VCUG was obtained annually if indicated. Families were asked to report on side effects, compliance, behaviour, continence, and overall satisfaction. Blood samples and electrocardiogram (EKG) were obtained at entry and every 6 months to detect potential toxicity. Effectiveness was also assessed using the Patient Perception of Bladder Condition (PPBC) scale on a 6-point scale ranging from 1 to 6 (Table 1), ${ }^{17}$ at study initiation and every 6 months. Compliance was evaluated by monitoring pill containers and assiduity of monthly renewals, and 3 categories were used: medication taken $>90 \%, 50 \%$ to $89 \%$ or less than $50 \%$ of the time.

Results were documented based on subjective relief of symptoms, objective voiding diaries and UDS parameters (the latter 2 following the International Children's Continence Society [ICCS] classification $\left.{ }^{16}\right)$. Parents or patients supervised by their parents rated symptom relief efficacy on a questionnaire as complete cure (defined as complete dryness), improvement (reduction of at least $90 \%$ of incontinence episodes) or partial improvement (reduction of 50\%-89\%). Failure was defined as reduction of less than $50 \%$. Changes in voided volume, cystometric bladder capacity, bladder compliance and detrusor contractions were also recorded. Improvement in bladder capacity and decrease in number and intensity of detrusor contractions were correlated with improvement of incontinence symptoms.

Tolerability was assessed by documented side effects by parents/patients and graded as follows: none, mild (does not interfere with the patient's usual function), moderate (interferes to some extent) and severe (interferes significantly). Parents and teachers were asked to regularly comment on any changes in behaviour or cognitive functions as they are known to be associated with the use of anticholinergic medication. ${ }^{18,19}$

Clinical variables were compared across groups using the Pearson chi-square test for categorical data. Continuous data were analyzed by Student t or Mann-Whitney $U$ tests. The normality of distribution was assessed using the ShapiroWilk W-test. Patients were censored when data were lacking. The Wilcoxon signed-rank or paired t tests were used for comparisons of treatment effects within each group. A $p$ value of less than 0.05 was considered statistically significant, and all tests were two-sided. All statistical analyses were performed using SPSS Statistics 21.0 Software (SPSS Inc., Chicago IL).

\section{Results}

The study included 244 patients (112 girls, 132 boys). Of these, 53 patients had NDO and 191 had DO. They

\begin{tabular}{lcc}
\hline $\begin{array}{l}\text { Table 1. The 6-item patient perception of bladder condition } \\
\text { (PPBC) scale. Bladder Condition-Subject Assessment }\end{array}$ \\
$\begin{array}{l}\text { My bladder } \\
\text { condition: }\end{array}$ & does not cause me any problems at all \\
& 3 & causes me some very minor problems \\
3 & causes me some minor problems \\
4 & causes me (some) moderate problems \\
5 & causes me severe problems \\
6 & causes me many severe problems \\
\hline
\end{tabular}


were enrolled and prospectively followed for a minimum of 5 months after administration of solifenacin (median 19.0 months). The solifenacin dose was increased until the incontinence was resolved or until side effects occurred. The mean age at initiation of solifenacin was 9.2 years $( \pm$ standard deviation [SD] 4.0 years). The mean duration of treatment with solifenacin was 21.0 months ( $\mathrm{SD} \pm 16.6$ months) (Table 2 ). Fourteen patients stopped medication because of side effects after an average of 12.3 months. All patients were started on solifenacin at 0.07 to $0.33 \mathrm{mg} / \mathrm{kg}$ to a daily maximum of $10 \mathrm{mg}$. The dosage of solifenacin was significantly increased during treatment $(p<0.0001)$ (Table 4).

\section{Efficacy}

Continence improved in all patients except 1 . The improvement of $100 \%$ (complete dryness) was documented in 88 patients $(36 \%),>90 \%$ in $78(32 \%)$ and a $50 \%$ to $89 \%$ reduction in 77 (32\%). This correlated directly with changes in urodynamic parameters since mean voided volumes, cystometric bladder capacity and maximum pressure of detrusor contractions all improved significantly with treatment for both NDO and DO patients (Table 3). The number of incontinence episodes per day was significantly decreased from initiation of solifenacin to the end of the study $(p<0.0001)$ (Table 4). Subjective improvement was also noticed with mean PPBC scores decreasing from 4.4 $(\mathrm{SD} \pm 0.7)$ at baseline to $1.8(\mathrm{SD} \pm 0.7 ; p<0.0001)$ at the end point (Table 4) (Fig. 1).

At completion of follow-up, 171 patients were still on the medication, while 13 patients were on dosage tapering because of improvement of their condition. Sixty patients had stopped solifenacin completely: 14 because of side effects, 37 because they were dry (and remained dry up until last follow-up), and 9 (all NDO) who were refractory to treatment and underwent other treatment modalities ( 7 had intravesical injection of botulinum toxin and $2 \mathrm{had}$ an augmentation enterocystoplasty) (Table 5$)$. The overall success rate was $91 \%(221 / 244)$, more specifically $94 \%$ (179/191) for DO and $79 \%(42 / 53)$ for NDO, which is significantly different $(p=0.013)$.

\section{Tolerability}

All EKG and blood tests remained normal. No deterioration of the upper urinary tract was noted on subsequent ultrasound and VCUG. No side effects were reported by 175 $(72 \%)$ patients. A subgroup of $46(19 \%)$ described mild side effects: xerostomia $(n=25)$, constipation $(n=18)$, blurred vision $(n=1)$, headache $(n=1)$, and insomnia $(n=1)$, while 9 experienced moderate xerostomia. Side effects were more often reported by NDO patients (38\%) compared to DO $(26 \%)$ patients, but this difference was not significant $(p=0.07)$. However, 14 patients discontinued treatment because of side effects (Table 5); 2 NDO patients due to severe constipation $(n=1)$ and insomnia $(n=1)$; and 12 DO patients for aggressive behaviour $(n=7)$, xerostomia $(n=2)$, diarrhea $(n=1)$, constipation $(n=1)$ or xerophtalmia $(n=1)$.

Of the 218 patients spontaneously voiding, 10 developed significant PVR ( $\geq 20 \mathrm{~mL}$, as per the ICCS), 7 improved following additional intensification of biofeedback, and 3 children responded to the addition of an alpha-blocker. Three symptomatic UTI were documented, 2 involving patients with high PVR. One patient developed multiple cavities secondary to xerostomia. No other adverse events were reported. Compliance to medication was excellent ( $>90 \%)$. Only 5 patients with partial improvement took their medication less than $75 \%$ of the time.

\section{Discussion}

Pediatric OAB can be a lifelong problem and it should be addressed as soon as recognized to improve the child's symptoms, prevent renal damage and decrease the risk of developing severe and refractory symptoms in their adult life. ${ }^{1}$ Once non-pharmacological methods fail to provide significant improvement, antimuscarinics can be implemented. ${ }^{20}$

Aside from oxybutynin, which is FDA-approved for children, reports on use in children with $\mathrm{OAB}$ are provided for tolterodine, trospium and propiverine. ${ }^{5-12}$ Hoebeke and colleagues performed a retrospective uncontrolled study in 138 children with therapy resistant non-neurogenic overactive bladder whom they treated with solifenacin for a mean of 23 months. They found solifenacin effective with an overall $85 \%$ response rate, a full response in more than $50 \%$ and side effects in only $6.5 \%$ of their cohort. ${ }^{21}$

\begin{tabular}{|c|c|c|c|c|c|c|}
\hline \multirow[t]{2}{*}{ Type of bladder dysfunction } & \multicolumn{2}{|c|}{ Gender } & \multirow{2}{*}{$\begin{array}{l}\text { Age at initiation of solifenacin } \\
\text { (years), mean (SD) }\end{array}$} & \multicolumn{2}{|c|}{ Voiding pattern } & \multirow{2}{*}{$\begin{array}{l}\text { Treatment duration } \\
\text { (months), mean (SD) }\end{array}$} \\
\hline & M & $\mathbf{F}$ & & Spontaneous & CIC & \\
\hline Neurogenic & 25 & 28 & $9.7(4.8)$ & 29 & 24 & $33.9(21.1)^{*}$ \\
\hline Non-neurogenic & 107 & 84 & $9.0(3.8)$ & 189 & 2 & $17.4(13.1)^{*}$ \\
\hline All & 132 & 112 & $9.2(4.0)$ & 218 & 26 & $21.0(16.6)$ \\
\hline
\end{tabular}




\begin{tabular}{|c|c|c|c|c|c|c|}
\hline \multirow{2}{*}{$\begin{array}{l}\text { Type of bladder } \\
\text { dysfunction }\end{array}$} & \multicolumn{2}{|c|}{ 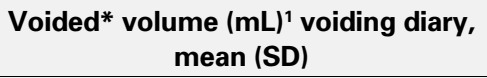 } & \multicolumn{2}{|c|}{$\begin{array}{l}\text { Urodynamic capacity }(\mathrm{mL}),{ }^{1} \text { mean } \\
\text { (SD) }\end{array}$} & \multicolumn{2}{|c|}{$\begin{array}{c}\text { Detrusor contractions }{ }^{4}(\mathrm{~cm} \mathrm{H} \mathrm{H}) \text {, } \\
\text { mean (SD) }\end{array}$} \\
\hline & Before & After & Before & After & Before & After \\
\hline Neurogenic & $137(81)^{2}$ & $304(132)^{2}$ & $163(90)^{3}$ & $338(173)$ & $62(27)$ & $22(19)$ \\
\hline Non-neurogenic & $107(51)^{2}$ & $245(104)^{2}$ & $128(56)^{3}$ & 340 (133) & $70(24)$ & $18(21)$ \\
\hline All & $113(60)$ & $258(113)$ & $145(76)$ & 339 (152) & $66(26)$ & $20(20)$ \\
\hline
\end{tabular}

SD: standard deviation; *Voided or catheterized volumes. "Bladder capacity evaluated by 3-day voiding diary and urodynamic studies (UDS) was significantly improved during solifenacin treatment; overall, neurogenic and non-neurogenic groups $(p<0.0001)$. ${ }^{2}$ Bladder capacity evaluated by 3-day voiding diary and UDS was significantly different between neurogenic and

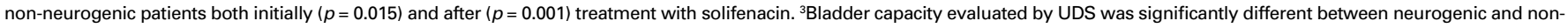

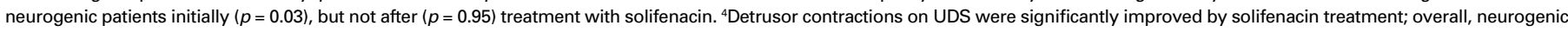
and non-neurogenic groups $(p<0.0001)$.

With this in mind, and considering the shortcomings of existing literature, we performed an open-label doseadjusted study of solifenacin use in children with DO and NDO. Subjective perceived benefit, overall satisfaction and continence rates were significantly better after the introduction of solifenacin, with greater benefits observed with higher doses.

Clinical and urodynamic parameters showed comparable improvements in both groups. Both groups had very good overall response, but there was a significant difference in success rates between neurogenic and non-neurogenic cases in favour of children with DO. This can be explained by the fact that neurogenic bladders are often more refractory to medical therapies, as pointed out by Horstmann and colleagues. ${ }^{22} \mathrm{~A} 94 \%$ success rate in the non-neurogenic group is therefore reassuring since other treatments, such as intravesical oxybutynin, sacral neuromodulation or botulinum toxin (with their inherent $5 \%$ to $11 \%$ risk of clean intermittent catheterization), ${ }^{23,24}$ would be deferred.

For non-responders or children responding only partially to therapy, initial urodynamics were less favourable (stronger uninhibited detrusor contractions and smaller bladder capacity). Longer treatment duration and/or a higher dose were therefore required before we could see improvement, if any, in their condition.

The discontinuation rate due to side effects was low $(6 \%)$, which is similar to other reports. ${ }^{25}$ It should be noted that, even if more than half of our cohort of children required an adult dose of solifenacin, most of the adverse effects were acceptably low in frequency, of minor severity and selflimited. Hypothetically, this could be partly explained by differences in the bioavailability in the pediatric population, although this would need confirmation as the pharmacokinetic behaviour of solifenacin in children and adolescents has not yet been published. ${ }^{26}$ Still, as for many other drugs on the market, since a $50-\mathrm{kg}$ woman in her twenties is allowed to take 5 and even $10 \mathrm{mg}$ of solifenacin (0.1-0.2 mg/kg) daily, consideration, for example, should be given to treat a $70-\mathrm{kg}$ 13 -year-old teenager with $7.5 \mathrm{mg}(0.1 \mathrm{mg} / \mathrm{kg})$. Therefore, even if this remains an off-label use of the medication, we believe our study supports a clinically nuanced approach with dose escalation for most refractory patients, always with caution and close follow-up to monitor side effects and biochemical parameters. As clinical judgement remains paramount to individualize such an approach, many authors have recently emphasized the need to focus on correction of "wetness" since emotional well-being, friendships and learning opportunities were clearly affected for children living with voiding dysfunction. ${ }^{27-29}$

Moreover, in our cohort medication was stopped or decreased in 50 patients $(20 \%)$ once continence and expected bladder capacity were reached and maintained (Table 5). This is an important finding when counselling patients and parents who might be concerned about taking lifelong medication. Patience is paramount in achieving the hoped-for results; discontinuing medication too early might bring us back to square one with reappearance of symptoms which would be discouraging for both the patient and the doctor.

We recognize the limitations of our study, namely the lack of a control group to take into account the placebo effect and the possibility that increases in bladder capacity can be secondary to age rather than to treatment, ${ }^{15}$ although treatment is only one of many parameters defining improve-

Table 4. Continence status and Patient Perception of Bladder Condition (PPBC) in relation to solifenacin dosage

\begin{tabular}{|c|c|c|c|c|c|c|}
\hline \multirow{2}{*}{$\begin{array}{l}\text { Type of bladder } \\
\text { dysfunction }\end{array}$} & \multicolumn{2}{|c|}{ Incontinence ${ }^{1}$ events / day, (SD) } & \multicolumn{2}{|c|}{ Dosage $(\mathrm{mg} / \mathrm{kg})^{2}$, mean (SD) } & \multicolumn{2}{|c|}{ PPBC score ${ }^{3}$ mean (SD) } \\
\hline & Before & After & Before & After & Before & After \\
\hline Neurogenic & $3.4(0.9)$ & $0.6(0.7)$ & $0.17(0.07)$ & $0.31(0.14)$ & $4.7(0.7)$ & $2.0(0.8)$ \\
\hline Non-neurogenic & $2.8(0.8)$ & $0.5(0.5)$ & $0.16(0.05)$ & $0.26(0.12)$ & $4.4(0.7)$ & $1.8(0.7)$ \\
\hline All & $2.9(0.9)$ & $0.5(0.6)$ & $0.16(0.06)$ & $0.27(0.12)$ & $4.4(0.7)$ & $1.8(0.7)$ \\
\hline
\end{tabular}

SD: standard deviation; Before: mean number of incontinence episodes per day on 3-day voiding diary when initiating study; After: mean number of incontinence episodes per day on 3-day

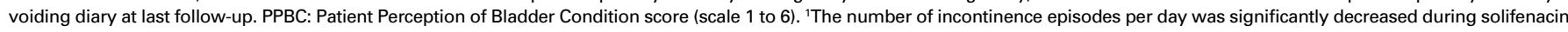
treatment; overall, neurogenic and non-neurogenic patients $(p<0.0001) .{ }^{2}$ The dosage of solifenacin was significantly increased during treatment; overall, neurogenic and non-neurogenic groups $(p<0.0001)$. ${ }^{3}$ PPBC scores significantly decreased from start to end of study; overall, neurogenic and non-neurogenic groups $(p<0.0001)$. 


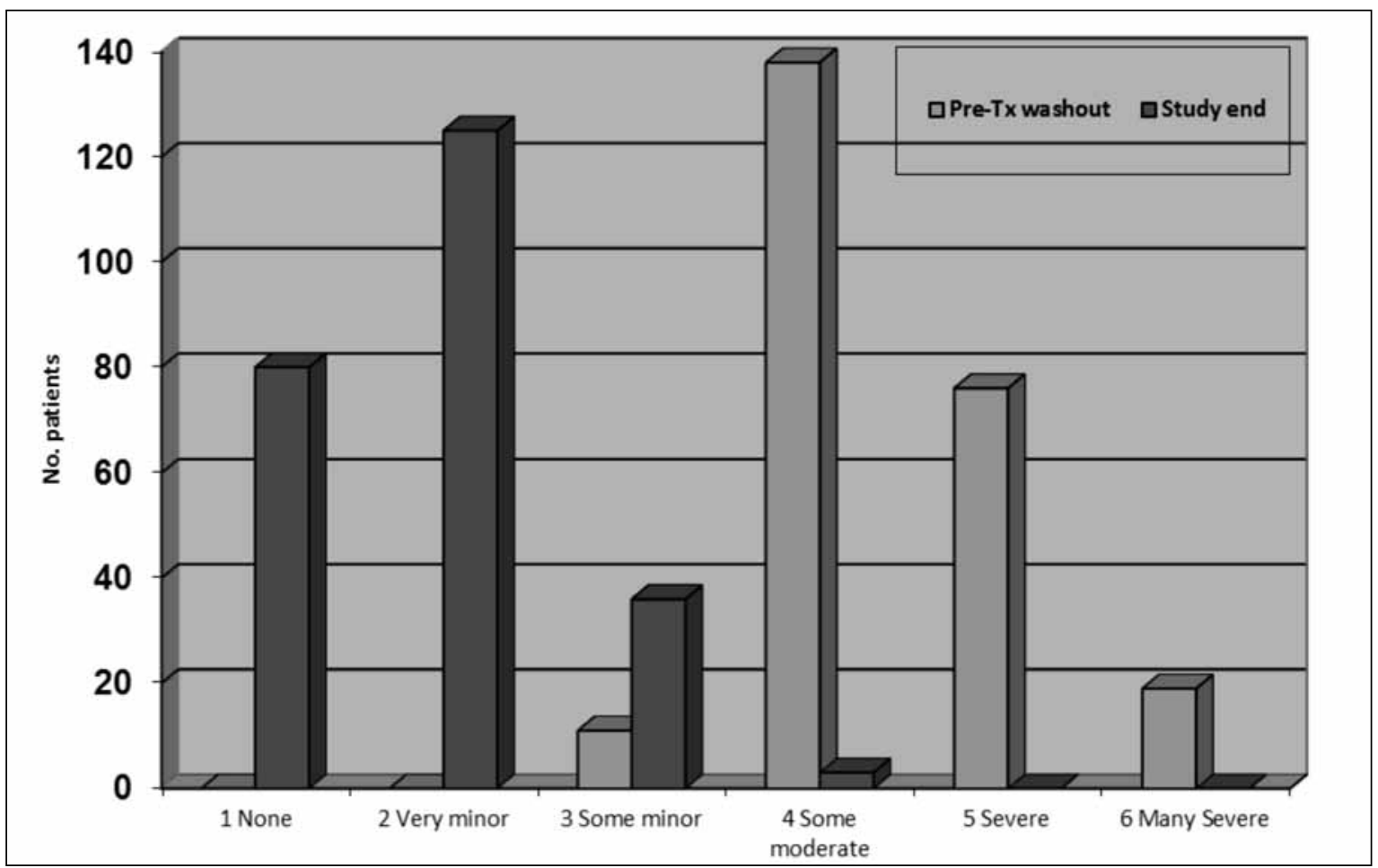

Fig. 1. Patient Perception of Bladder Condition (PPBC) scores at pre-study washout and at study end. Lower scores indicate improvement.

ment. Nevertheless, our study is the first prospective longterm study on solifenacin use in pediatric DO/NDO. With its flexibility of doses, large size of cohort, and high compliance rates, our study compares favourably to other studies in this field. ${ }^{4,30}$

Finally, our results allow us to again support the use of solifenacin to treat pediatric patients with refractory $O A B$, as antimuscarinics offer no panacea since they all target the same receptor in the detrusor smooth muscle. With the recent introduction and use in the adult population of mirabegron, a $\beta 3$-agonist with a different mechanism of action, studies are eagerly awaited to explore its effects among pediatric patients, as it appears to be an attractive innocuous molecule.

\section{Conclusion}

Bearing in mind the previously stated caveats of our study, we reiterated the efficacy and safety of solifenacin to treat children with idiopathic and neurogenic overactive bladder refractory to oxybutynin or tolterodine. Pediatric patients and their families were very satisfied with the use of this offlabel medication. Although a very encouraging and promising pharmacological alternative, randomized controlled studies are required before obtaining official approval and recommending this agent for routine use in children with $\mathrm{OAB}$.

Competing interests: Dr. Nadeau, Dr. Schröder, Dr. Moore, Dr. Genois, Dr. Lamontagne, Dr. Hamel, Dr. Pellerin and Dr. Bolduc all declare no competing financial or personal interests.

\begin{tabular}{|c|c|c|c|c|c|c|c|c|}
\hline \multirow{2}{*}{$\begin{array}{l}\text { Type of bladder } \\
\text { dysfunction }\end{array}$} & \multicolumn{3}{|c|}{ Still on medication, dosage } & \multicolumn{4}{|c|}{ Stopped medication } & \multirow{2}{*}{ Total } \\
\hline & Stable & $\uparrow$ & $\downarrow$ & Dry & S/E & Botox & Augment & \\
\hline Neurogenic & 20 & 18 & 2 & 2 & 2 & 7 & 2 & 53 \\
\hline Non-neurogenic & 120 & 13 & 11 & 35 & 12 & 0 & 0 & 191 \\
\hline All & 140 & 31 & 13 & 37 & 14 & 7 & 2 & 244 \\
\hline
\end{tabular}

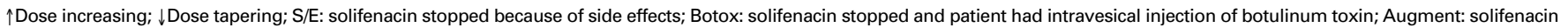
stopped and patient had augmentation enterocystoplasty. 
This paper has been peer-reviewed.

\section{References}

1. Tekgul S, Hoebeke P, Canning D, et al. Diagnosis and management of urinary incontinence in childhood. In: Incontinence-4th International Consultation. Paris: Health Publications; 2009.

2. Nepple KG, Cooper CS. Management of bladder dysfunction in children, Management of bladder dysfunction in children. UpToDate, Wolters Kluwer Health; 2013. http://www.uptodate.com/contents/managementof-bladder-dysfunction-in-children. Accessed March 25, 2014.

3. Chapple CR. What do we really know about antimuscarinic therapy for adult neurogenic detrusor overactivity? Eur Urol 2012;62:831-3. http://dx.doi.org/10.1016/i.eururo.2012.05.069

4. Madhuvrata $P$, Singh $M$, Hasafa $Z$, et al. Anticholinergic drugs for adult neurogenic detrusor overactivity: a systematic review and meta-analysis. Eur Urol 2012;2:816-30. http://dx.doi.org/10.1016/i. eururo.2012.02.036

5. Bolduc S, Upadhyay J, Payton J, et al. The use of tolterodine in children after oxybutynin failure. BJU Int 2003;91:398-401. http://dx.doi.org/10.1046/i.1464-410X.2003.04085.x

6. Hiälmås K, Hellström AL, Mogren K, et al. The overactive bladder in children: A potential future indication for tolterodine. BJU Int 2001;87:569. http://dx.doi.org/10.1046/j.1464-410X.2001.00084.x

7. Munding $M$, Wessells $H$, Thornberry $B$, et al. Use of tolterodine in children with dysfunctional voiding: An initial report. J Urol 2001;165:926-8. http://dx.doi.org/10.1016/S0022-5347(05)66576-7

8. Reinberg Y, Crocker J, Wolpert J, et al. Therapeutic efficacy of extended release oxybutynin chloride, and immediate release and long acting tolterodine tartrate in children with diurnal urinary incontinence. J Urol 2003;169:317. http://dx.doi.org/10.1016/S0022-5347(05)64115-8

9. Nijman RJ, Borgstein NG, Ellsworth P, et al. Long-term tolerability of tolterodine extended release in children 5-11 years of age: Results from a 12-month, open-label study. Eur Urol 2007;52:1511-7. http://dx.doi. org/10.1016/j.eururo.2007.05.002

10. Lopez Pereira P, Miguelez C, Caffarati J, et al. Trospium chloride for the treatment of detrusor instability in children. J Urol 2003;170:1978-81. http://dx.doi.org/10.1097/01.ju.0000085667.05190.ad

11. Marschall-Kehrel D, Feustel C, Persson de Geeter C, et al. Treatment with propiverine in children suffering from nonneurogenic overactive bladder and urinary incontinence: Results of a randomized placebo-controlled phase 3 clinical trial. Eur Urol 2009;55:729-38. http://dx.doi.org/10.1016/i.eururo.2008.04.062

12. Kim WJ, Lee DG, Lee $S W$, et al. Efficacy and safety of propiverine in children with overactive bladder. Korean J Urol 2012;53:275-9. http://dx.doi.org/10.4111/kju.2012.53.4.275

13. Smulders RA, Krauwinkel WJ, Swart PJ, et al. Pharmacokinetics and safety of solifenacin succinate in healthy young men. J Clin Pharmacol 2004;44:1023-33. http://dx.doi.org/10.1177/0091270004267592

14. Kreder KJ. Solifenacin. Urol Clin North Am 2006;33:483-90. http://dx.doi.org/10.1016/i. ucl.2006.06.008

15. Bolduc $S$, Moore $K$, Nadeau $G$, et al. Prospective open label study of solifenacin for overactive bladder in children. J Urol 2010;184:1668-73. http://dx.doi.org/10.1016/i.juro.2010.03.124
16. Neveus $T$, von Gontard A, Hoebeke $P$, et al. The standardization of terminology of lower urinary tract function in children and adolescents: Report from the Standardisation Committee of the International Children's Continence Society. J Urol 2006; 176:314-24. http://dx.doi.org/10.1016/S0022-5347(06)00305-3

17. Coyne KS, Matza LS, Kopp Z, et al. The validation of the patient perception of bladder condition (PPBC): A single-item global measure for patients with overactive bladder. Eur Urol 2006;49:1079-86. http:// dx.doi.org/10.1016/i.eururo.2006.01.007

18. Sommer $B R, O^{\prime}$ Hara $R$, Askari N, et al. The effect of oxybutynin treatment on cognition in children with diurnal incontinence. J Urol 2005; 173:2125-7. http://dx.doi.org/10.1097/01.ju.0000157685.83573.79

19. Giramonti KM, Kogan BA, Halpern LF. The effects of anticholinergic drugs on attention span and short-term memory skills in children. Neurourol Urodyn 2008;27:315-8. http://dx.doi.org/10.1002/nau.20507

20. Gormley EA, Lightner DJ, Burgio KL, et al. Diagnosis and treatment of overactive bladder (non-neurogenic) in adults: AUA/SUFU Guideline. J Urol 2012;188:2455-63. http://dx.doi.org/10.1016/i. juro.2012.09.079

21. Hoebeke P, De Pooter J, De Caestecker K, et al. Solifenacin for therapy resistant overactive bladder. J Urol 2009;182:2040-4. http://dx.doi.org/10.1016/i.juro.2009.05.100

22. Horstmann M, Schaefer T, Aguilar Y, et al. Neurogenic bladder treatment by doubling the recommended antimuscarinic dosage. Neurourol Urodyn 2006;25:441-5. http://dx.doi.org/10.1002/nau.20289

23. Visco AG, Brubaker L, Richter HE, et al. Anticholinergic therapy vs. onabotulinumtoxina for urgency urinary incontinence. N Engl J Med 2012;367:1803-13. http://dx.doi.org/10.1056/NEJMoal 208872

24. Dmochowski R, Chapple C, Nitti VW, et al. Efficacy and safety of onabotulinumtoxinA for idiopathic overactive bladder: A double-blind, placebo controlled, randomized, dose ranging trial. J Urol 2010;184:241622. hittp://dx.doi.org/10.1016/i.juro.2010.08.021

25. Shamliyan $T$, Wyman JF, Ramakrishnan $R$, et al. Benefits and harms of pharmacologic treatment for urinary incontinence in women: A systematic review. Ann Intern Med 2012;156:861-74. http://dx.doi. org/10.7326/0003-4819-156-12-201206190-00436

26. Doroshyenko 0, Fuhr U. Clinical pharmacokinetics and pharmacodynamics of solifenacin. Clin Pharmacokinet 2009;48:281-302. http://dx.doi.org/10.2165/00003088-200948050-00001

27. Senior J. Exploring the life experiences of young people with bladder dysfunction (Abstract 4867). Presented at Moving Beyond Pediatric Incontinence. Toronto, Ontario, Canada, June 6-8 2013.

28. Wolfe-Christensen C, Veenstra AL, Kovacevic L, et al. Psychosocial difficulties in children referred to pediatric urology: A closer look. Urology 2012;80:907. http://dx.doi.org/10.1016/j.urology.2012.04.077

29. Wolfe-Christensen C, Manolis A, Guy WC, et al. Bladder and bowel dysfunction: Evidence for multidisciplinary care. J Urol 2013;190:1864-8. http://dx.doi.org/10.1016/i.juro.2013.05.012

30. Buser $N$, Ivic $S$, Kessler TM, et al. Efficacy and adverse events of antimuscarinics for treating overactive bladder: Network meta-analyses. Eur Urol 2012;62:1040-60. http://dx.doi.org/10.1016/i. eururo.2012.08.060

Correspondence: Dr. Stéphane Bolduc, Pediatric Urologist, Assistant Professor, Clinician-Scientist, Division of Urology, Centre Hospitalier Universitaire de Québec (CHUQ, CHUL), 2705, Boul. Laurier, R-1742, Québec, QC GIV 4G2; sbolduc_2002@yahoo.ca 